\title{
Is anything just plain good?
}

\author{
Mahrad Almotahari • Adam Hosein
}

(C) Springer Science+Business Media Dordrecht 2014

\begin{abstract}
Geach (Analysis 17: 33-42, 1956) and Thomson (J Philos 94:273-298, 1997, Normativity, 2008) have argued that nothing is just plain good, because 'good' is, logically, an attributive adjective. The upshot, according to Geach and Thomson, is that consequentialism is unacceptable, since its very formulation requires a predicative (non-attributive) use of 'good'. Reactions to the argument have, for the most part, been uniform. Authors have converged on two challenging objections (Ross, The right and the good, 1930; Pidgen, Philos Q 40:129-154, 1990; Arneson, Analysis, 70:731-744, 2010; Smith, Analysis 70:715-731, 2010; Sturgeon, Analysis 70:744-753, 2010; Kraut, Against absolute goodness, 2011). First, although the logical tests that Geach and Thomson invoke clearly illustrate that 'good', as commonly used, is an attributive, they don't show that 'good' lacks an intelligible predicative interpretation. Second, even if the English word 'good' fails to express the property of goodness, we can just stipulate that ' $g o o{ }^{*}$ ' expresses goodness and thus formulate consequentialism accordingly. The second objection is one way of voicing skepticism about the method of drawing substantive philosophical conclusions from considerations about ordinary language. In this essay, we present an argument, inspired by Geach and Thomson, which isn't susceptible to the same objections but which supports the same conclusion. The significance of our argument for ethics is obvious; it challenges the intelligibility of standard consequentialism, and even certain forms of non-consequentialism. One might be inclined to think that a more sophisticated consequentialism, which relies on 'good \{possible
\end{abstract}

\footnotetext{
M. Almotahari ( $₫)$

University of Illinois, Chicago, 1423 University Hall, 601 South Morgan Street, Chicago, IL 60607, USA

e-mail: almotaha@uic.edu
}

\section{A. Hosein}

Philosophy Department, University of Colorado, Boulder, UCB 232, Boulder, CO 80309, USA

e-mail: adam.hosein@colorado.edu 
world/state of affairs/outcome \}' instead of just 'good', evades the criticism. But we explain why the criticism can't be so easily evaded.

Keywords Attributive adjectives ' 'Good' - Goodness - Consequentialism . Peter Geach · Judith Jarvis Thomson

\section{Introduction}

The most natural answer to the question, is anything just plain good, is yes. People seem to have no trouble thinking of examples. Pleasure is just plain good, they might say, or knowledge, beauty, and love-surely love is just plain good. But some philosophers have argued that nothing is unqualifiedly good. It's not that they think everything falls somewhere between bad, mediocre, and just-shy-of-good, or that they embrace some sort of sweeping value nihilism. It's that 'good' isn't the sort of word whose grammar permits it to be used without further qualification. (Nor, for that matter, is 'bad', but we'll focus on 'good'.) The qualification needn't be explicit; it can be supplied by extra-linguistic context, such as when someone says, 'The food was good', and thereby communicates that the food was good to eat.

Why think that English grammar forbids the use of 'good' without qualification? In short, the answer is that 'good' is, logically, an attributive, not a predicative, adjective. Here is how Peter Geach explains the matter:

There are familiar examples of what I call attributive adjectives. 'Big' and 'small' are attributive; ' $x$ is a big flea' doesn't split up into ' $x$ is a flea' and ' $x$ is big', nor ' $\mathrm{x}$ is a small elephant' into ' $\mathrm{x}$ is an elephant' and ' $\mathrm{x}$ is small'; for if these analyses were legitimate, a simple argument would show that a big flea is a big animal and a small elephant a small animal. [...] On the other hand, in the phrase 'a red book' 'red' is a predicative adjective in my sense [...] for 'is a red book' logically splits up into 'is a book' and 'is red'. [...] 'good' and 'bad' are always attributive, not predicative, adjectives. (1956, p. 64, emphasis added) ${ }^{1}$

Judith Jarvis Thomson develops the point somewhat differently:

Peter Geach said that the adjective "good" is not a predicative adjective: it is an attributive adjective. We can express what he had in mind as follows.

Let $\mathrm{K}_{1}$ and $\mathrm{K}_{2}$ be any pair of kinds of things, and let "adj" be any adjective. "Adj" is a predicative adjective just in case the conjunction of the propositions

$\mathrm{A}$ is an adj $\mathrm{K}_{1}$

and

$\mathrm{A}$ is a $\mathrm{K}_{2}$

\footnotetext{
${ }^{1}$ Geach is often cited as the originator of the observation that 'good' is attributive but it was anticipated by Ross (1930), who made rather less of it than Geach did. According to Kamp (1975, p. 127), the observation is so old that it can't be precisely traced to its origin. One respondent informed us that essentially the same point can be found in Aristotle. More recently, the observation reappears in Ziff (1960), von Wright (1963), and Foot (1985).
} 
entails the proposition

$A$ is an adj $\mathrm{K}_{2}$.

[...] "Good" is also an attributive adjective, since the conjunction of

(4) $\mathrm{A}$ is a good tennis player

and

(5) A is a chess player

doesn't entail

(6) A is a good chess player (2008, pp. 4-5; see also Thomson 1997).

The reason why inferences of the sort Geach and Thomson describe are invalid for attributive adjectives, ' $a j_{\text {attributive }}$, is that being an $\operatorname{adj}_{\text {attributive }} \mathrm{K}$ does not consist in being adjattributive and being a $\mathrm{K}$. There simply is no property of being adjattributive, according to Thomson. A fortiori, there is no set of things that have that property with which the extension of 'is a $\mathrm{K}$ ' can be intersected to yield the extension of 'is an $\operatorname{adj}_{\text {attributive }} \mathrm{K}^{\prime}$.2 Furthermore, as (4)-(6) appear to illustrate, 'good' is an attributive. So Thomson infers that there is no property of being good. On the basis of these considerations, then, one might think nothing is just plain good.

Beyond challenging the most natural answer to the question, is anything just plain good, the Geach-Thomson argument threatens standard consequentialism, according to which one ought to act so as to produce more, not less, of what's good. ${ }^{3}$ Formulating the doctrine in this way makes it clear that standard consequentialism requires a predicative use of the word 'good'. It requires that there be such a thing as goodness such that our actions ought to bring about more instances of it. ${ }^{4}$ Since there isn't any such thing, according Geach and Thomson (hereafter, G\&T), standard consequentialism simply won't do as a viable ethical theory.

\footnotetext{
${ }^{2}$ This explanation is also given in the linguistics literature. See Kennedy (2012, p. 334). We should note that our use of 'predicative' and 'attributive' diverges slightly from the way these terms are used in linguistics. Linguists typically use them to distinguish between genuine predicates and expressions that happen to modify a noun phrase. We understand the claim that 'good' is sometimes predicative to amount to the thesis that 'good' sometimes expresses a property, goodness, which can then be predicated of various kinds of thing.

${ }^{3}$ Authors who either defend this form of consequentialism, or take it seriously enough to discuss it, include Moore (1903), Dewey and Tufts (1908, pp. 224-225), Broad (1930, pp. 206-207), Ross (1930), Frankena (1963, p. 13), Rawls (1971, p. 24), Smart (1973, p. 9), Scheffler (1988, p. 1), Kagan (1998, p. 26), Brown (2011, p. 751), Parfit (2011, pp. 235-236), Temkin (2012, pp. 24-25), and Willenken (2012, p. 545).

${ }^{4}$ Our formulation of standard consequentialism in terms of goodness presupposes realism about properties. The presupposition is mainly for expository purposes; it makes our job a bit easier. Of course, we acknowledge that a consequentialist may well embrace nominalism. Anyone who accepts both consequentialism and nominalism will think (roughly) that what one ought to do is produce more true instances of ' $a$ is good', where the truth of the instances isn't susceptible to further analysis in terms of the subject's standing in some relation (instantiation) to an abstract entity such as goodness (Cf. Quine 1948 and Devitt 1980). Just as the nominalist about color properties believes that there are red things (particular houses, roses, sunsets) without there being some further entity, redness, to which they stand in the instantiation relation, the value nominalist believes that there are good things (perhaps houses, roses, sunsets) without there being some further entity, goodness, to which they stand in the instantiation relation. As we explain in Sect. 3, the use of 'good' in the phrase 'good thing' is a predicative use of the word.
} 
Even some forms of non-consequentialism are vulnerable. Consider the question, how ought we to respond to goodness in the world? One answer-the standard consequentialist's - is that we ought to maximize instances of it. But there are other answers, which are characteristic of certain kinds of non-consequentialism. Perhaps, for instance, our goal should be to avoid damaging good things that already exist, or to act in ways that express respect for instances of goodness, or maybe just to have certain attitudes, such as admiration, towards good things. Arguably, certain rightsbased and Kantian views rely on thoughts of this kind, though we don't want to get embroiled in matters of interpretation here. ${ }^{5}$ At the very least, there appears to be room in logical space for a non-consequentialism of the sort we describe. But if G\&T's argument succeeds, then the space of options is far less expansive than one might have initially thought. For if there isn't any such thing as goodness, then there isn't any such thing as an instance of goodness. A fortiori, there isn't any such thing as an instance of goodness that we ought to, say, express respect toward, admire, or refrain from damaging.

Unsurprisingly, given its radical implications, G\&T's argument has met with considerable resistance. Critics have converged on two major objections (Ross 1930; Pidgen 1990; Arneson 2010; Smith 2010; Sturgeon 2010; Kraut 2011). First, although the logical tests that G\&T invoke clearly illustrate that 'good' is sometimes - maybe even often - an attributive, they don't show that 'good' lacks an intelligible predicative interpretation. Consider the passage from Geach above. Why does he assume that 'good' is, as he puts it, always used attributively? Thomson is more careful than Geach. She observes, "It is certainly possible for an adjective to have two uses, only one of which is attributive" (2008, p. 13). But, in the end, her argument too relies on the same assumption that 'good' is always used attributively, for otherwise the inference from (i) " "Good" is an attributive' and (ii) 'There is no property of being adjattributive ' to (iii) 'There is no property of being good' would be blocked. The reason is that 'good', as it occurs in (iii), may well be a predicative occurrence of the term. What rules this possibility out, presumably, is that (i) amounts to the claim that every occurrence of 'good' is an attributive (2008, pp. 8-9).

To sharpen the criticism here, it helps to consider an adjective that has both a predicative and an attributive use. Consider 'famous'. Surely Jones can be a famous philatelist (that is, famous as, or for, a philatelist) without being just plain famous. Therefore, 'famous' has an attributive interpretation. But it can also be used predicatively, for Muhammad Ali is surely just plain famous. Similarly, one might

\footnotetext{
5 Francis Kamm, for instance, appears to endorse a non-consequentialist response to value: "It is not our duty to bring about [...] agent-neutral value, but only to respect the constraints that express its presence" (Kamm 1992, p. 386). Korsgaard (1983) and Langton (2007) have discussed creating and responding to value in a Kantian theory. See also Schapiro (2001) for discussion of different responses to value in utilitarianism, rational intuitionism, and Kantian constructivism. Whether Kant himself was a nonconsequentialist of the sort we're describing is, we believe, a controversial question.
} 
think, pleasure is just plain good, even though, as (4)-(6) illustrate, 'good' certainly has an attributive interpretation. ${ }^{6}$

G\&T anticipate this sort of objection and exploit the same strategy to deflect it. They consider a range of cases that one might plausibly treat as intelligible, predicative uses of the word 'good' and offer ways of paraphrasing them so as to reveal implicit qualification. For instance, 'pleasure is good' might be elliptical for 'pleasure is good for you'; 'beauty is good' may amount to 'beauty is good to observe'; and so on. Without going into detail, the trouble with this response is that it puts G\&T on the defensive, constantly having to convince their interlocutors that one's initial impression about the case at issue is mistaken. If the conclusion of the Geach-Thomson argument is true, and there really isn't anything that's just plain good, then certainly some of our initial impressions are mistaken. But adopting this strategy means that the premises of the argument are also very controversial.

We said that the Geach-Thomson argument has come under fire from two directions. We've discussed the first. The second is that, even if the English word 'good' fails to express the property of goodness, we can stipulate that 'good*' expresses goodness and thus formulate consequentialism accordingly. This objection is one way of voicing skepticism about the method of drawing substantive philosophical conclusions from considerations about ordinary language. No one familiar with the advance of science would expect that ordinary English has the expressive resources to offer an accurate and complete representation of the nonnormative aspects of the world. That's why inquirers often introduce specialized vocabulary and employ formal notation. Why should an accurate and complete representation of the normative aspects of the world be any different? Acknowledging the distinction between 'good' and 'good*' is thus no more worrisome, it may seem, than acknowledging the distinction between 'relativistic mass' and 'proper mass'.

In this essay, we present an argument, inspired by G\&T, which isn't susceptible to the same objections. The significance of our argument for ethics is obvious; it challenges the intelligibility of standard consequentialism. The argument should also be of interest to philosophers outside of ethics, since it presents a new route

\footnotetext{
6 'Famous' is discussed in Thomson (2008, p. 14) and credited to Matthew Hanser. In order to distinguish 'good' from 'famous' in such a way as to rescue her argument, Thomson asks a rhetorical question: "What assures us that 'famous' does have this second use is that we know what the property of being (simply) famous $i s$-it is the property of being (simply) well known. What is the property that Ross claims is ascribed to knowledge, or pleasure, by a philosopher who says 'That is good' of it?" The implication is that our inability to say, in other terms, what it is for something to be (simply) good should undermine our confidence in the intelligibility of predicative 'good'. But this move is unlikely to persuade Thomson's interlocutors. There are several reasons why.

First, it may well be that 'good', when used predicatively, is unanalyzable. Moore (1903), arguably the most important consequentialist in the twentieth century and the author to whom Thomson addresses her arguments, explicitly defends the unanalyzability of predicative 'good'. Furthermore, some contemporary writers are sympathetic to Moore's view (see Kraut (2011, p. 182)). Second, Thomson's argument overgeneralizes. If an inability to analyze predicative 'good' tells in favor of its unintelligibility, why then should not our inability to analyze 'truth', 'existence', etc. tell in favor of their unintelligibility? Finally, if Thomson's response to the challenge involving 'famous' were successful, it would have rendered the initial argument in terms of Geach's observation unnecessary.
} 
from considerations about ordinary language to conclusions about substantive and controversial philosophical issues. Before we proceed, however, let us reiterate that our argument targets standard consequentialism. We discuss the prospects for a viable though somewhat more sophisticated consequentialism after the argument has been fully spelled out. We doubt that a viable consequentialism can be formulated in terms of, say, 'good \{possible world/state of affairs/situation/ outcome \}', largely for the same reason that we doubt the viability of standard consequentialism. But it will take some time to fully explain why.

\section{The new argument}

We begin with a straightforward presentation of our argument, postponing further discussion and defense until all of the pieces are on the table.

Suppose for the sake of argument that the property of being (simply) good exists. We believe that the considerations below put tremendous pressure on this natural supposition.

(P1) If there's a property of being good, then we can entertain the property of being good in thought.

(P2) If we can entertain the property of being good in thought, then we can use the word 'good' predicatively in a literal utterance of ' $a$ is good' and thus express the property of being good.

(P3) If we can use the word 'good' predicatively in a literal utterance of ' $a$ is good' and thus express the property of being good, then we can use the word 'good' predicatively in a literal utterance of ' $a$ is a good $\mathrm{K}$ ' and thus express the property of being good.

(P4) But we can't use the word 'good' predicatively in sentences of the form ' $a$ is a good $\mathrm{K}$ '.

(C1) Therefore, contrary to our initial supposition, there's no property of being good.

(P5) If there's no property of being good, then it's not the case that what we ought to do is produce more instances of goodness.

(C2) Therefore, standard consequentialism is false.

The logic of the argument is unimpeachable (certainly in this context). We arrive at (C1) via repeated applications of modus tollens on (P1)-(P4). Assuming 'It is not the case that $S$ ' entails that ' $S$ ' is false, (P5) and (C1) jointly entail (C2), with the help of modus ponens. ${ }^{7}$ Hopefully, the premises will strike the reader as plausible at a first pass. But we expect questions and concerns to arise. So we would like to defend each individual step, explaining as we proceed how our argument improves upon G\&T's.

Consider (P1). What would it take to resist it? One would have to think that the property of being good exists, but that we aren't able to entertain it in thought. But

\footnotetext{
7 We intend for (P1)-(P3) and (P5) to be interpreted as material conditionals.
} 
then how is one able to even affirm its existence? The position here is incoherent, since affirming the existence of unqualified goodness requires that one entertain it in thought. To be clear, accepting (P1) does not require committing oneself to the view that if something exists, then it can be entertained in thought. We certainly acknowledge that there may well be things-extremely large numbers, for example, or bizarre properties beyond our ken - that we're simply unable to entertain in thought. What we deny is the coherence of simultaneously affirming a singular (as opposed to a general) existential proposition about some particular thinggoodness, for instance-and denying that it can be entertained in thought.

Assuming that we can entertain the property of being good in thought, how can we convey such thoughts by means of English? One rather direct way, it would seem, is by using the word 'good' in a sentence like 'Pleasure is good' while in a literal frame of mind. Sentences of the relevant sort would be true iff the subject term referred to something that fell in the extension of 'good', in which case the use of 'good' would be predicative. (P2) encapsulates this attractive thought. When we say that this thought is attractive what we mean is that the conditional thought is attractive, namely, if we can entertain goodness, then, in some contexts, we're able to express it with unqualified uses of the word 'good'. Ultimately, we want to challenge the supposition that unqualified goodness can be entertained in thought, but we take it on board momentarily for the sake of argument. As we will show, the supposition is unstable; assuming it leads to rejecting it.

We actually find it somewhat difficult to motivate (P2). It's a little hard to think of wholly independent considerations to which one might appeal that are even more plausible than (P2). The premise seems hardly in need of defense. But we can think of two ways to engender confidence here.

First, consider the sort of view one would have to hold in order to reject $(\mathrm{P} 2)$. One would have to maintain that, even though one is able to think the thought that pleasure is an instance of goodness, and even though one is able to intend to communicate that thought linguistically, one can never do so by simply uttering the words 'Pleasure is good'. Saying 'Pleasure is good' somehow frustrates one's communicative intention. We are confident that this view will strike most, if not all, readers as significantly less plausible on its face than (P2). In any case, it will strike consequentialists who often perform such speech acts as completely unacceptable (Kagan 1998, p. 26; Moore 1903; Parfit 2011, pp. 235-236; and Temkin 2012, pp. 24-25, to name a few).

One caveat: (P2) doesn't require a commitment to (nor is it at all motivated by) the implausible view that if we're capable of entertaining something, $x$, in thoughtif, say, we have a concept of $x$-then our concept of $x$ is lexicalized. We may well possess concepts for which there isn't any corresponding word in natural language. But our interlocutors don't think the concept of goodness is like that. According to them, the concept of goodness plays an important role in practical deliberation. When, according to our interlocutors, an agent concludes that, for example, some particular state of affairs is good, she might, on the basis of her judgment, form the intention to bring it about. Furthermore, she may be called on to justify her intention to bring it about to others, or to justify the steps she's already taken toward that end. To think that we have a concept of goodness that has eluded lexicalization would be 
to think that the agent is incapable of doing so by simply saying, "That state of affairs is good, and its goodness is what motivated me to bring it about". We know of no consequentialist who would be happy to say something like this (in advance of our argument).

Second, if goodness can be entertained in thought, then surely the expression 'goodness' refers to it, and one can express the thesis that goodness exists with the English sentence 'Goodness exists'. (Of course, one option available to our interlocutors is to deny that even 'goodness' refers to goodness. But the resulting view begins to look very strange: goodness exists, but 'goodness' fails to refer to it. How, then, were we able to state the view just now? Are there any terms in English that denote goodness? If so, why do they succeed where 'goodness' fails? If not, then goodness is simply ineffable. Again, we know of no consequentialist who accepts such a radical view). Now, how could it be that the nominal form of the word 'good' (namely, 'goodness') refers to goodness when the adjectival form fails to express it? Plausibly, 'good' and 'goodness' are semantically related to each other in such a way that the latter refers to the property that the former expresses. So, if you take 'goodness' to refer to goodness, then you ought to acknowledge that, at least sometimes, 'good' expresses goodness. And that's just what standard consequentialists do; they say pleasure, knowledge, beauty, or whatever you like, is good, intending to convey that goodness is realized. We're confident, then, that our interlocutors will take (P2) to be acceptable. Additional considerations in favor of (P2) will be presented when we discuss ' $g o o d *$ ' and the 'stipulation response' near the end.

Consider (P3). Abbreviating a bit, it says that if one can use 'good' predicatively in ' $a$ is good', then one can also use 'good' predicatively in ' $a$ is a good K'. Why should one accept (P3)? Well, suppose that the use of 'good' in 'Pleasure is good' expresses goodness. Then 'Pleasure is good' is true iff pleasure falls in the extension of 'good'. But then surely the use of 'good' in 'Pleasure is good' can be combined with a common noun, 'sensation', to yield a complex verb phrase, 'is a good sensation', whose extension is determined by intersecting the extensions of 'good' and 'sensation'. Now, if the extension of 'is a good sensation' in 'Pleasure is a good sensation' is the intersection of the extensions of 'good' and 'sensation', then the use of 'good' in 'Pleasure is a good sensation' will satisfy G\&T's tests for predicativity. None of this should be surprising, though, since other predicatives behave in exactly the same way. For example, one can combine the word 'black' in 'KITT is black' with the word 'car' to yield 'KITT is a black car', and doing so preserves the predicativity of 'black'.

Admittedly, 'black', unlike 'good', doesn't have an attributive use. So one might worry that the terms are importantly dissimilar. To bypass the worry, and provide further support for (P3), it helps to analogize 'good' and 'famous', as critics of the Geach-Thomson argument would like to. 'Famous', you'll recall, has both a predicative and an attributive use.

\footnotetext{
${ }^{8}$ We're alluding, of course, to the Knight Industries Two Thousand ('KITT' for short) — the car depicted in the 1980s TV series, Knight Rider, starring David Hasselhoff.
} 
Suppose that seven-time Wimbledon champion, Roger Federer, is an amateur chess player. Suppose A happens to know of Federer's chess playing pastime. Suppose further that B is ignorant about Federer's career in tennis. She doesn't know that Federer is a professional tennis player, nor does she know that Federer is famous. Finally, suppose A is aware of B's ignorance. Now imagine A and B are walking past a tennis court; A spots Federer, points to him and says, 'That guy is a famous chess player'. If that's all A says, then B is likely to form the belief that Federer is famous as a chess player. But suppose A follows up with, 'Of course, he's not famous for his chess playing.' Then the suggestion that Federer is famous as a chess player is canceled. Consider:

That guy is a famous chess player. Of course, he's not famous for his chess playing.

The overall effect of A's entire speech act, then, is to convey that Federer is both just plain famous and a chess player, which renders his initial use of 'famous' in 'That guy is a famous chess player' predicative by the lights of Geach's test. The take-home message is that even explicitly qualified uses of the word 'famous'-uses of the word in a literal utterance of ' $a$ is a famous $\mathrm{K}$ ' - can express the property of being just plain famous. So, if, like 'famous', 'good' has both a predicative and an attributive use, then one would expect that, like 'famous', the predicative interpretation can sometimes be elicited in explicitly qualified uses of the word.

But—and here's the pivotal move of our argument, expressed in (P4) - there simply is no sentence of the form ' $a$ is a good $\mathrm{K}$ ' such that the use of 'good' is predicative in it. Just to be clear, at this stage we aren't asserting anything as heavy handed as G\&T's assumption that the use of 'good' always has an attributive interpretation. The point is simply that when 'good' occurs with an explicit qualification, as in the phrase 'good tennis player', then its use in that context is attributive.

Why accept (P4)? Well, if 'good' can be used predicatively in sentences of the form ' $a$ is a good $\mathrm{K}$ ', then one should expect that the arguments immediately below, (A1)-(A3), have both a valid as well as an invalid reading: the former corresponding to the predicative use of 'good'; the latter corresponding to the attributive use.

(A1)

Tomás de Torquemada was a good professional torturer. ${ }^{9}$

Tomás de Torquemada was a chess player.

Therefore, Tomás de Torquemada was a good chess player.

Pain is a good source of creativity.

Pain is a sensation.

Therefore, pain is a good sensation.

\footnotetext{
9 Tomás de Torquemada was Grand Inquisitor of Spain in the fifteenth century, and oversaw the torture, forced conversion, and ultimate expulsion of many Spanish Muslims and Jews.
} 
(A3)

That one has a headache is a good excuse to leave the party.

That one has a headache is a \{possibility/fact/state of affairs\}.

Therefore, that one has a headache is a good \{possibility/fact/state of affairs\}.

But we, and our informants, are simply unable to detect a valid reading. In fact, not a single critic of G\&T's original argument defends the thought that such arguments have a valid reading. The consensus among the critics appears to be that one can coherently grant the observation that such arguments lack a valid reading and simply deny G\&T's conclusion that goodness doesn't exist. Our argument indicates that this consensus view is a mistake: in conjunction with (P1)-(P3), the logical point that Geach made, and that Thomson reiterated, can't be conceded without commitment to the conclusion that there isn't any such thing as goodness.

We're prepared to concede, as several respondents have observed in discussions of this material, that there are instances of the relevant argument scheme-

$a$ is a good $\mathrm{K}_{1}$.

$a$ is a $\mathrm{K}_{2}$.

Therefore, $a$ is a good $\mathrm{K}_{2}$.

- that can be assigned a valid interpretation. For example, consider a minor variation on Thomson's (4)-(6), which we presented at the outset.

(A4)

Roger Federer is a good tennis player.

Roger Federer is a chess player.

Therefore, Roger Federer is a good chess player.

Now, suppose we're in a context, C, where the question under discussion is whether any tennis players are morally good people. (Someone in C was struck by how many tennis players are cheaters, and thus raised the question whether any tennis players are virtuous.) In such a setting, one might naturally utter the sentence, 'Roger Federer is a good tennis player', and the sentence would appear to express a meaning that validates (A4). For if Federer is a good tennis player in the sense made salient at C-the sense in which it's incompatible with being a cheater-then if Federer is a chess player, it should follow that he is, in the very same sense of 'good', a good chess player.

But none of this undermines what we've said so far. The reason is that if 'good' can be used predicatively in sentences of the form ' $a$ is a good K', then it should have such a use generally, not just when ' $\mathrm{K}$ ' is replaced with certain noun phrases, like 'tennis player', or when the sentence is interpreted against a specific context, like C. The predicative reading of 'good', in instances of the schematic phrase 'good $\mathrm{K}$ ', might be easier to detect when ' $\mathrm{K}$ ' is replaced with certain noun phrases, but whether the predicative reading is present at all should be insensitive to which noun is used. For, in principle, one could think that just about any $\mathrm{K}$ is good simpliciter, 
including the relevant $\mathrm{Ks}$ in (A1)-(A3). But the absence of a valid reading in (A1)(A3) shows that 'good' can't, in general, be used predicatively in such sentences.

More can be said in support of (P4). Note that it's not hard to detect a valid reading in the corresponding argument involving 'famous'. It simply requires adding a "cancellation clause" to the conclusion.

(A5)

Tomás de Torquemada was a famous professional torturer.

Tomás de Torquemada was a chess player.

Therefore, Tomás de Torquemada was a famous chess player—of course, he wasn't famous as a chess player.

The informants we have consulted confirm our judgment about this argument. In contrast, (A1)-(A3) aren't improved at all by adding a cancellation clause.

\section{$(\mathrm{A} 1 *)$}

Tomás de Torquemada was a good professional torturer.

Tomás de Torquemada was a chess player.

Therefore, Tomás de Torquemada was a good chess player-of course, he wasn't good as a chess player.

\section{$(\mathrm{A} 2 *)$}

Pain is a good source of creativity.

Pain is a sensation.

Therefore, pain is a good sensation-of course, it's not good as a sensation to experience.

That one has a headache is a good excuse to leave the party.

That one has a headache is a \{possibility/fact/state of affairs .

Therefore, that one has a headache is a good \{possibility/fact/state of affairs \} - of course, it's not good as a \{possibility/fact/state of affairs \}.

The conclusion of each argument immediately above lacks a true reading. They strike us, and our informants, as simply contradictory. Since these arguments lack a valid reading, we can conclude that qualified uses of 'good' —as in 'good professional torturer', 'good source of creativity', 'good sensation', 'good excuse to leave the party', etc.- - fail to have a predicative interpretation.

Now, before moving on, we should make one more observation. It might seem that we've raised a puzzle regarding (A4). We've seen that one can't use 'good' predicatively in sentences of the form ' $a$ is a good $\mathrm{K}$ '. This means that the uses of 'good' in (A4) aren't, in any context, predicative. Is it a puzzle, then, that (A4) appears to be valid in C? Not really: there's a very plausible explanation for the validity of (A4) in C that's entirely compatible with (P4). A particular way of being good-namely, being a morally good person-is made salient in C. So, plausibly, 'Roger Federer is a good tennis player' expresses the proposition that Rodger Federer is a morally good person and a tennis player. Thus (A4) has a valid reading 
not because its first premise is being used predicatively but because it has a complex attributive reading supplied by $\mathrm{C}^{10}$

Our argument relies on the claim that certain constructions (the conclusions in $(\mathrm{A} 1 *),(\mathrm{A} 2 *)$, and $\left(\mathrm{A} 3^{*}\right)$ ) fail to elicit a true reading. Similar claims have been made elsewhere in philosophy. For example, Kripke (1980, p. 48-49) argued that proper names and natural kind terms are rigid designators on the grounds that, when plugged into the sentence schema below, the resulting sentence fails to have a reading on which it's true.

$a$ might have not been $a$

'Nixon might have not been Nixon', for instance, and 'pain might have not been pain' lack true readings. Therefore, Kripke concluded, 'Nixon' and 'pain' are rigid designators. To preempt skepticism about our semantic judgments, we would like to explain, by way of comparison with Kripke's argument, how the pivotal considerations we rely on should not be understood.

We would like to suggest that when evaluating a sentence, $S$, for a true readingwhether $S$ is one of our sentences or one of Kripke's-one should remain neutral with respect to any controversial hypothesis about the semantics of key terms occurring in $\mathrm{S}$. The reason is that evaluating $\mathrm{S}$ for coherence is supposed to be a diagnostic test for adjudicating whether any particular semantic hypothesis about the terms is correct. It simply will not do, then, to respond to Kripke's claim about the rigidity of 'Nixon' by momentarily assuming a sort of standard (un-rigidified) descriptivism and then assessing 'Nixon might have not been Nixon' for coherence. ${ }^{11}$ Likewise, it simply will not do to respond to our claims by assuming

\footnotetext{
${ }^{10}$ Mightn't the predicative reading of 'good' just be the reading made salient in C? No, not if one takes the meaning of predicative 'good' to apply univocally across a wide range of kinds. For the property of being a morally good person isn't the property that consequentialists want to ascribe to events, states of affairs, possibilities, or sensations, though they do often speak as if bare occurrences of 'good' expressed one and the same property — goodness-that particular persons, events, states, possibilities, and sensations can have. The reading of 'good' in C on which (A4) is valid isn't the sort of reading that can modify so wide a range of kinds.

${ }^{11}$ David Lewis rejects Kripke's judgment about the rigidity of 'pain' by committing just this sort of error. He writes,

If the concept of pain is the concept of a state that occupies a certain causal role, then whatever state does occupy that role is pain. If the state of having neurons hooked up in a certain way and firing in a certain pattern is the state properly apt for causing and being caused, as we materialists think, then that neural state is pain. But the concept of pain is not the concept of that neural state. ("The concept of..." is an intensional functor.) The concept of pain, unlike the concept of that neural state which in fact is pain, would have applied to some different state if the relevant causal relations had been different. Pain might have not been pain. The occupant of the role might have not occupied it (1980, p. 125, emphasis added).
}

Now it's certainly true that the occupant of the pain-role might have not occupied that role, but that's a true interpretation of the sentence 'pain might have not been pain' only if the italicized clause in the passage is indeed true - only if, that is, the concept of pain is in fact the concept of a state that occupies a certain causal role. But that's an extremely controversial and not at all obvious claim-one that we should abstract away from in passing a semantic judgment about 'pain might have not been pain', since the judgment is supposed to be one source of evidence about what sort of concept the concept of pain is. If analytic functionalism is true, then 'pain might have not been pain' has a coherent reading-granted-but 
the predicativity of 'good' in the relevant constructions and then evaluating 'Torquemada is a good chess player, but not good as a chess player' for coherence. The relevant question is not whether there's some reasonably attractive semantic hypothesis that, if true, would render $\mathrm{S}$ coherent. The relevant question is whether $\mathrm{S}$ really is coherent. It's precisely for this reason that semanticists gather data from theoretically uninitiated but competent language users. And it's for the same reason that we cite the reactions of our naive informants as corroborating evidence.

So far, we've defended (P1)-(P4), which jointly entail (C1).

(C1) Therefore, contrary to our initial supposition, there is no property of being good.

(P5) If there is no property of being good, then it is not the case that what we ought to do is produce more instances of goodness.

(C2) Therefore, standard consequentialism is false.

Two observations are worth making before we comment on (P5) and conclude.

The first observation is that at no point in formulating our argument are we forced to assume the sort of defensive posture that G\&T are forced to assume, and that many critics find unconvincing. G\&T consider sentences where 'good' appears to have a predicative use. Their response, you'll recall, is to offer ways of paraphrasing them so as to reveal implicit qualification. Not a single premise in our argument requires for its acceptance that a credible paraphrase strategy be offered for sentences of the form ' $a$ is good'. Nor, more generally, do we assume that the use of 'good' in those sentences is not predicative. Rather, we demonstrate that the use of 'good' in those sentences can't be predicative. We take this to be a tremendous advantage, since the critics are no more likely to accept such a premise than they are to accept the conclusion of the argument. In short, our argument isn't susceptible to the criticism that it unjustifiably requires 'good' to always occur as an attributive. We were careful to formulate our claims in such a way that dispenses with this worrisome step in the Geach-Thomson argument.

The second observation is that, once we arrive at (C1), introducing 'good*' won't help the consequentialist at all. Our argument doesn't merely justify the semantic conclusion that the English word 'good' fails to express the property of goodness; it establishes the metaphysical thesis that there's no property of goodness for any new word to pick out. In the absence of that property, standard consequentialism is an extremely implausible view about what we ought to do.

Still, there may be some residual temptation to think that our argument moves too quickly from conclusions about language to conclusions about what properties there are. "Look", the critic might say, "even if there is no word we can use to attribute the property of goodness, that property still plausibly exists. And to talk about it we just need to define the word 'good*' in the appropriate way." The 'stipulation response', as we'll call it, is suggested by remarks in Arneson (2010, p. 733), who criticizes G\&T as follows.

Footnote 11 continued

that's partly what's at issue when Kripke asks us to assess the sentence, 'pain might have not been pain', for coherence. 
Let's suppose that the English language, along with all other languages people on earth use, at the beginning of the twentieth century lacked the resources to express the idea that good is a simple, non-natural property. What blocks Moore, or anyone, from inventing the conceptual resources he needs to express the theoretical ethical claims he wants to make? Just as Albert Einstein needed to make conceptual innovations in order to formulate the scientific theories he wished to advance, so too a moral theorist might find it necessary or useful to define new terms to facilitate the expression of new concepts [...].

The stipulation response, as Arneson makes clear, concedes that on no occasion has the use of 'good' succeeded at expressing the property of goodness. Even so, he suggests, there is a property of goodness. Arneson is thus advocating the denial of (P2).

It's worth emphasizing what a surprising position Arneson's is. All this time we've been surrounded by instances of unqualified goodness. We're told that at least some of the following things, which we frequently come across in everyday life, have that property: pleasure, knowledge, beauty, and love. And yet we lack any ability to express in English the property that sets these things apart from all others. Surely, one might think, if this property existed, we would have the conceptual and linguistic resources to discuss it before introducing ' $g$ ood*'.

Arneson's analogy with the language of science supports our claim. Clearly, he is right that the advance of science often requires conceptual and linguistic innovation. In many cases, scientists have posited objects and properties that couldn't have been discussed without changing the vernacular. But there's a natural explanation for why ordinary language was lacking in expressive power before the scientific advance: the relevant phenomena were often not easily observable and had to be discovered using sophisticated technologies or complicated reasoning that relied on indirect methods. It's hardly a surprise that there was no name for the Higgs boson prior to the development of particle physics: it simply is not directly observable in the course of ordinary life, nor is it easily identified as part of the explanation for puzzling phenomena, nor does it play a role in practical deliberation.

Goodness, as ordinarily understood by moral philosophers, is crucially unlike the Higgs boson. It's supposed to be a property that we regularly encounter-a property that can be discerned by ordinary people using ordinary means, and that often plays an important role in ordinary deliberation. The standard consequentialist assumes that we all have relatively direct access to which things are just plain good, and can rely on our judgments about such things to help us figure out how to act. To be sure, there has been substantial debate about exactly which things are, in the end, good. Should we just include pleasure, or also knowledge, beauty, love, and so on? But the most basic datum for the standard consequentialist is still the sheer impression ordinary people are supposed to have that some things and not others are good. How bizarre that no one ever bothered to introduce an English word to convey this impression, even though it impinges on ordinary thought and action regularly!

What if goodness is simply harder to identify than consequentialists assume? Could the stipulation response be rescued? It would be very surprising if in order to defend consequentialism from our attack one had to think that goodness is extremely difficult to encounter and fix on. That would be, in itself, an important 
result for ethics. But, furthermore, it's important to be clear about exactly how obscure goodness would have to be for the response to succeed. It wouldn't do to simply think that people may have trouble discerning exactly which things are good and thus often make mistakes. That sort of obscurity is consistent with (P2). The claim would have to be that goodness is so obscure to us that it has eluded our every effort to linguistically represent it: that ordinary people have never even asked the question whether certain things are good. For if 'good' fails to express goodness, then 'goodness' fails to refer to it; and why should any other term of our language succeed at denoting goodness when 'good' and 'goodness' fail? There may well be a respectable form of Platonism according to which the recognition of goodness in things is difficult, but the claim required to deny (P2) is much more radical than any familiar view of that kind.

Furthermore, the stipulation response implies that there's a stark and peculiar contrast between the property of being good in a way and the property of being good. While the former property can be expressed quite easily in English, the latter can't be. Why? Advocates of the response can point to nothing about our language or the world that would suggest that there should be such an asymmetry. We have the construction ' $a$ is a good K', but we also have the construction ' $a$ is good'. Why does the former manage to hit the obvious target but not the latter? Surely not, as we have emphasized, because the property of being good would be massively more elusive.

We addressed the stipulation response in part because we think it articulates a general suspicion among philosophers that reflection on features of ordinary language can't yield substantive ethical or metaphysical conclusions. One might worry that we haven't said enough to suppress this general suspicion, but readers should bear two points in mind. First, our argument relies on two specific claims that effectively bridge the gap between world, mind, and language. (P1) establishes a connection between the existence of goodness and our capacity to represent it in thought. (P2) establishes a connection between our capacity to represent goodness in thought and the means by which we convey such thoughts with ordinary language. A good deal of this section has been spent defending these premises precisely because we are aware that there's a general sort of anxiety about our methodology. Second, unless this general anxiety can be articulated so as to challenge either (P1) or (P2) directly, it doesn't qualify as an objection. We don't have the space to consider all or very many of the ways in which the general suspicion might take a specific form, but we believe that the considerations in favor of (P1) and (P2) are strong enough to put a great deal of pressure on our interlocutors. In any event, neither (P1) nor (P2) is objectionable for the reasons that people often cite in response to G\&T's argument. So even if one or the other premise were falsified by a consideration that managed to escape our attention, our argument would still be an improvement over G\&T's.

Let us turn, finally, to (P5) and our conclusion. This premise seems unassailable. In the absence of goodness, surely it is not the case that what we ought to do is produce more instances of that property. Standard consequentialism just is the view that what we ought to do is promote that property. Thus, (P5) and (C1) clearly entail our conclusion, that standard consequentialism is false.

One might react to our argument by adopting one of two attitudes. One might think the conclusion of our argument is so obviously false that it constitutes a 
puzzle. Alternatively, one might think our argument is sound. We incline toward the latter option. Either way, though, there's more work to do. If one takes the argument to be a puzzle, then the challenge is to diagnose the hitherto unidentified error. Familiar objections are ineffective. If one takes the argument to be sound, then the challenge is to explain the apparent intelligibility of certain ways of speaking. Neither task is trivial. Admittedly, we don't now have a completely satisfying story to tell about why some seemingly predicative uses of the word 'good' appear meaningful. People certainly say things such as 'Experiencing love for the first time was good', or 'The situation in Benghazi was not good'. Our argument shows that, surprisingly, they aren't thereby expressing the property of being good. What, then, are they saying? This lingering question should not be taken to imply that our argument is unworthy of serious consideration. Suppose a nominalist about mathematics constructs a new criticism of Platonism. Whether the nominalist's argument is deserving of serious consideration isn't, we believe, hostage to a successful, nominalistically halal, paraphrase of quantum mechanics. Our argument should be judged according to the same standard.

Although we don't have a completely satisfying account of why apparently predicative uses of the word 'good' appear meaningful, we can take the first few steps toward a credible story. One should bear in mind that interpretation is governed by a principle of charity to which people effortlessly conform. Interpreters are so reluctant to treat their interlocutor's speech acts as utter nonsense that, typically, as long as there's some meaningful statement in the vicinity, they will take the speaker to be drawing attention to that. To illustrate, consider the sentence 'More people have read books by Marquez than I have'. Hinzen (2006, p. 131) reports that, in the rapid-fire pace of an ordinary conversation, it "will usually get a meaning ascribed to it (perhaps, I am not the only one who has read books by Marquez). But its literal meaning becomes opaque the moment we think about it." Sometimes, all that's required for the impression of intelligibility is syntactic well-formed-ness. For example, when one reads Lewis Carroll's poem, 'Jabberwocky', one feels as though the meaning of, say, "All mimsy were the borogoves" is just within reach. Furthermore, it's a widely shared belief among philosophers of language, linguists, and cognitive scientists that extra-linguistic context plays a crucial role in modifying and enhancing the meanings conveyed by "semantically incomplete" constructions. Examples of this sort of phenomenon are so numerous and so familiar that it's hard to know which to choose. A waiter says, 'The ham sandwich is waiting for his check', and his interpreter understands, based on the broader context, that the person who ordered the ham sandwich is waiting for his check (Nunberg 1978). It may be that sentences of the form ' $a$ is good' are semantically incomplete in the same way, and that extra-linguistic context supplies the relevant qualification. ${ }^{12,13}$ Or it may be that some mild form of

\footnotetext{
12 As we indicated at the beginning, this is essentially G\&T's approach to analyzing such constructions. But, to emphasize, while we're somewhat sympathetic to it, our central argument, unlike G\&T's, doesn't rely on contextualism about 'good'. In fact, the contextualist strategy may seem much more promising now that we have in hand an argument that the relevant expressions can't express unqualified goodness.

13 According to one recent and highly attractive formal account, all gradable adjectives, like 'expensive' and 'good', are doubly context sensitive: context supplies a dimension along which the item is said to be
} 
expressivism is true, and what appear to be assertive utterances of ' $a$ is good' aren't really assertions at all, but merely recommendations. Or perhaps some hybrid story that combines interpretive charity, contextualism, and expressivism provides the best explanation. What we want to emphasize is that there are a number of options available and familiar theoretical tools at our disposal. This ought to encourage optimism. But we will reserve further discussion for another occasion.

We'd like to conclude this section by returning to a point we made earlier but which deserves emphasis. G\&T's argument has been widely criticized. Critics no doubt disagree with each other on how best to think about the meaning of predicative 'good' but they agree on this much: one can grant the basic logical point that Geach made about 'good', and that Thomson reiterated, without having to abandon standard consequentialism. If nothing else, we have shown that this consensus is mistaken.

\section{Sophisticated consequentialisms}

The target so far has been standard consequentialism, the view (very roughly) that one ought to act so as to produce more instances of unqualified goodness. Hopefully, the reader now agrees that this view is unacceptable. This is not a trivial result. Standard consequentialism is the view held or discussed by G. E. Moore, John Dewey and James H. Tufts, C. D. Broad, and W. D. Ross. It may appear to be less popular among recent authors, who tend to use 'good \{thing/ possible world/state of affairs/situation/outcome\}' rather than just plain 'good'. But it's often clear from the broader context in which such expressions are used that, typically, even recent authors intend to be expressing the idea of a thing, world, state of affairs, situation, or outcome that is (simply) good. For instance, Smart writes, "Act-utilitarianism is the view that the rightness or wrongness of an action is to be judged by the consequences, good or bad, of the action itself. Ruleutilitarianism is the view that the rightness or wrongness of an action is to be judged by the goodness or badness of the consequences of a rule that everyone should perform the action in like circumstances" (1973, p. 9). Kagan says that "we should pick the act with the best results. We should pick the act that best promotes the good" (1998, p. 26, emphasis added). Even more recently, Derek Parfit says,

Many things are good or bad [...]. Such things have certain kinds of properties or features that would, in some situations, give us or others reasons to respond to these things in certain ways.

What we can promote are events, in the wide sense of 'event' that also covers acts and states of affairs. Events can be good or bad either as an end or as a means to some end. (2011, pp. 235-236)

Footnote 13 continued

expensive or good, and a threshold along a certain scale determined by the relevant dimension such that items on the right side of the threshold are expensive or good (Kennedy 2007). 
And a number of authors are happy to ask, for example, how the goodness of individual lives or beautiful trees affects the goodness of outcomes. ${ }^{14}$ Since these views presuppose the existence of goodness, our argument targets them as well.

Of course, one might simply think that we should maximize, say, aggregate pleasure, which wouldn't require appealing to goodness of any kind. This thought could still reasonably be described as a consequentialist view. All the same, our conclusion reorients the dialectic in a way that levels the playing field. Nonconsequentialists are no longer in the awkward position of having to concede that, despite the fact that ing would produce more instances of unqualified goodness, it's impermissible all the same to $\phi$. Such a concession borders on the paradoxical at worst and the ad hoc at best. It's probably for this very reason that Moore said that "the assertion 'I am morally bound to perform this action' is identical with the assertion 'This action will produce the greatest amount of good in the Universe", (Moore 1903, p. 147). Far better to eliminate goodness from the inventory of what there is and thereby avoid the discomfort of having to make such a large concession.

There are, of course, other popular versions of consequentialism, and we would like to explain how our argument applies to them.

Here is a familiar (though admittedly rough) way of stating consequentialism that doesn't begin, like standard consequentialism, with the claim that there is a property of goodness. We can rank possible worlds as better or worse worlds. The right action is the one, of those available, that would make actual the highest ranked world. This version of consequentialism, it might be said, requires only that there be a property of being good in one particular way: as a possible world. Actually, it might be said that what is needed is just the relation of being a better possible world. For ease of presentation, and to preserve continuity with the previous section, it will be helpful to assume, plausibly, that there's a relation of being a better possible world only if there's a property of being a good possible world. In any case, our arguments - both in this and the previous section — can be harmlessly reformulated (if the reader wishes) in terms of being (simply) better than and being a better possible world.

Is sophisticated consequentialism viable? For it to succeed, a couple of constraints have to be met. Firstly, the use of 'good' in 'good possible world' must be genuinely attributive. Secondly, the property of being good as a possible world has to be capable of playing the appropriate role in a consequentialist theory. In particular, it has to be the sort of property of which it seems we are required to bring about more instances. We think that there is no use of 'good possible world' that meets the first constraint, and that, if there were such a use, then the property it picked out would not be capable of playing the role required to meet the second constraint. Let us explain these points in turn.

As a general matter, merely adding a noun complement to an adjective only sometimes creates an attributive reading of the adjective. ${ }^{15}$ For some adjectives,

\footnotetext{
${ }^{14}$ For a recent example, see Temkin (2012, pp. 24-25). Temkin's book is in fact called Rethinking the Good.

15 It's important to keep in mind at this stage how our use of 'attributive' diverges from its standard use in linguistics. See footnote 2.
} 
such as 'red', no attributive reading can be elicited, whichever noun is used. In the sentences, 'That is a red car' or 'He wore a red shirt', 'red' is not used attributively, despite the presence of 'car' and 'shirt'. For other adjectives, such as 'famous', it depends which noun complement we add. For instance, 'He is a famous imam' clearly has an attributive reading, expressing that he is famous in a particular way, namely, as an imam. By contrast, 'That is a famous thing' doesn't seem to elicit an attributive reading of 'famous'. Plausibly, when you say that such-and-such is a famous thing you don't express that it's famous in any particular way; you express simply that it's famous. The word 'good', like 'famous', is only sometimes given an attributive reading by adding a noun complement. ${ }^{16}$ Consider, say, 'That is a good speed'. Surely this doesn't express that, say, $57 \mathrm{MPH}$ is good (simply) as a speed, though it might be used, in certain contexts, to express that $57 \mathrm{MPH}$ is good as a speed for getting home on time or for avoiding legal penalties. Sometimes additional context can allow a noun to help create an attributive reading, because the context adds some further implicit qualification. Strictly speaking, then, our question is when merely adding a certain noun complement creates an attributive reading.

Is 'possible world' the sort of noun that, when combined with 'good', generates an attributive reading? Two considerations suggest otherwise.

Firstly, where an adjective has an attributive reading we can expect arguments of the following sort to have an invalid reading. Consider:

Imran Khan is famous.

Imran Khan is a gardener.

Therefore, Imran Khan is a famous gardener.

We can read 'famous' in the conclusion of this argument attributively, so that it expresses Khan's being famous as, or for, a gardener. This creates an invalid reading of the argument. Khan's fame in general doesn't guarantee that he's famous in that particular way. By contrast, there's only a valid reading of the argument immediately below.

The prophet's sword is famous.

The prophet's sword is an object/a thing .

Therefore, the prophet's sword is a famous \{object/thing $\}$.

The explanation, we submit, is that 'object' and 'thing' don't generate an attributive use of 'famous'. The conclusion can't be understood to mean that, for instance, Muhammad's sword is famous in the distinctively 'thingy' sort of way. In general, both 'object' and 'thing' seem to function like this, failing to generate, with an adjective, an attributive reading that would block inferences of the kind just considered. $^{17}$ 'Possible world' (or, more colloquially, 'possibility') seems to work the same way, as does any term that, say, Aristotle might have included on his list of

\footnotetext{
16 Geach (1956, p. 34) made this point as regards the phrase 'good thing'.

17 Recall footnote 4, where we acknowledged the possibility of combining consequentialism with nominalism. The value nominalist, as we called her, maintains that there are good things but there isn't any such thing as goodness. In light of our observations above, value nominalism can't evade our
} 
ontological categories: 'state of affairs', 'outcome', 'situation', and so on. There is only a valid reading of the arguments immediately below.

That God doesn't exist is scary.

That God doesn't exist is a \{possibility/state of affairs/situation .

Therefore, that God doesn't exist is a scary \{possibility/state of affairs/ situation $\}$.

If using 'possibility' or 'possible world' as a complement with an adjective never generates an attributive reading of that adjective, then it doesn't generate an attributive reading of 'good' when used as its complement.

A second consideration (somewhat implicit in what we have said already) also suggests that 'possible world' isn't the sort of complement that generates an attributive reading of 'good'. Generally, where an adjective has an attributive reading (when concatenated with a certain noun) we can bring out that reading with certain phrases. We can say that he is famous for a tennis player, that the fungus is famous as a cure for arthritis, that the animal is famous insofar as it's the first of its kind, and that he is famous in his capacity as a model. In contrast, it's hard to understand what it would be for something to be famous for an object, as an object, insofar as it's an object, or in its capacity as an object. It's similarly difficult to understand what it would be for 103.3 KPH to be good (simply) as a speed, and so on. Plausibly, whenever there's an attributive reading of an adjective (with a particular noun complement) at least one of the locutions just deployed can be used to make it explicit, although perhaps not all of them can. Depending on the noun, one rather than another locution may be preferred. The only way we have found to generalize our point across possible noun complements is to use 'qua', as in 'Tong Po is famous qua kick-boxer', or 'Jerry is small qua mouse'. But we hesitate to rely too heavily on 'qua' since some people find it quite unnatural, and it may well be a term of art.

In any case, none of these locutions allows us to bring out an attributive use of 'good' in 'good possible world'. Consider:

It is good in a particular way: as a possible world.

It is good for a possible world.

It is good in its capacity as a possible world.

It is good insofar as it's a possible word.

It is good qua possible world.

We find it as hard to understand what it would be for something to be good (simply) as a possible world as to understand what it would be for something to be good

\footnotetext{
${ }^{17}$ Recall footnote 4, where we acknowledged the possibility of combining consequentialism with nominalism. The value nominalist, as we called her, maintains that there are good things but there isn't any such thing as goodness. In light of our observations above, value nominalism can't evade our objection: a commitment to the existence of good things involves a commitment to a meaningful use of predicative 'good'. Our arguments in defense of (P4) demonstrate that there isn't any such use of 'good'.
} 
(simply) as a speed. ${ }^{18}$ Try to use the same locutions but replacing 'possible world' with, say, 'way a world might be', 'possibility', 'state of affairs', 'outcome', or 'situation'. The difficulty persists.

In sum, though we appear to say that such-and-such is a good possible world, this doesn't show that there is a property of being a good possible world. ${ }^{19}$ This raises a puzzle: what do people mean, then, when they say that $a$ is a good possible world (or state of affairs, or outcome)? In other cases where adding a noun complement to an adjective doesn't generate an attributive reading one instead sticks with a predicative reading of the adjective when interpreting the whole phrase. For instance, we saw that adding 'car' to 'red' doesn't generate an attributive reading of 'red'. What happens instead is that 'red' in the phrase 'red car' retains the predicative meaning that it has in the absence of any noun complement. But it can't be that 'good' in the phrase 'good possible word' similarly retains a predicative reading because there is no predicative reading of 'good'. This puzzle is, we think, an instance of the more general challenge we acknowledged earlier, the challenge of explaining what 'good' means in the various sentences where it appears to have a predicative use. It will be solved when the more general puzzle is solved.

We have argued that the phrase 'good possible world' involves a predicative use of 'good'. But what if we're wrong and the phrase really does express the property of being good as a possible world? Could the property of being good as a possible world function at the base of a consequentialist theory? Well, are we required to bring about worlds or states of affairs that are good in this particular way?

Again it may help to compare 'good possible world' with 'famous object'. We have argued that 'famous' occurs predicatively in 'famous object'. But insofar as one can make sense of something being famous as an object, no object seems to be more famous in this way than any other object. Pete Sampras was certainly more famous as, or for, a tennis player than David Foster Wallace was. But neither was more or less famous as, or for, an object. To get at the same point in a slightly different way, consider which objects are merely a little famous as objects, and which are very famous as objects. We find ourselves incapable of answering the question. Why should that be? We suggest it's because the property of being famous as an object doesn't determine a ranking of objects.

What goes for 'famous object' seems to go for 'good possible world'. Insofar as we can make sense of a world's being good as a possible world, no world seems better in that way than any other. This means that the property of being a good possible world can't play the required sort of role in a consequentialist theory, since it will fail to generate a ranking of worlds and thus be unable to help pick out any particular actions as the ones we should perform. Furthermore, it's hard to know how much we should care in the first place about a world's being good as a possibility. Why should a world's being good in that way (namely, as merely

\footnotetext{
${ }^{18}$ Of course, it always sounds somewhat stilted to speak of something being good as a K, and so on. But ' $\operatorname{good}\{$ as a/for a/in its capacity as a/insofar as its a/qua $\}$ possible world' is bizarre in a way that makes it difficult to understand.

19 Thomson (2008, pp. 19-33) argues for the same point though in a different way. See Rosen (2012, pp. 676-677) for objections to her approach.
} 
something that could have been realized) be more important than its being good for its species diversity or good as an example of what humanity can achieve?

We believe the upshot is plain. The consequentialist can't rely on the property of being good, nor on the property of being a good possible world/state of affairs/ outcome/situation. Is there any other way of being good that she can rely on? One somewhat natural idea is that she could rely on the property of being good for people (or perhaps being good for sentient beings, or being good for us). For instance, it would be good for people if a way to prevent global warming were found. The consequentialist could rank worlds in terms of how good they are for people.

Is there a property of being good for people? According to some philosophers, a world, W1, is better for people than a world, W2, only if W1 would be a 'pareto improvement' over W2: if some people would be better off in W1 and no one would be worse off. ${ }^{20}$ Once there are conflicts of interest, where some people would be better off in W1 and others in W2, there is no fact about which would be better (or perhaps they are both equally good). But let's grant that we can make sense of one world being better for people than another-even where there are conflicts of interest-by aggregating costs and benefits to different people if that world were to be actualized. Some critics of Thomson have said that once such aggregation is allowed the consequentialist is easily able to state and defend her theory (Arneson 2010; Sturgeon 2010).

It seems plain that the fact that such-and-such would be good for people is a relevant consideration when considering what to do. But it seems unlikely that this property could play just the same role that goodness is thought to play in standard consequentialism. That such-and-such would bring about more instances of goodness is usually thought to provide not just $a$ reason for action but one which settles that you ought to do it. It seems bizarre to people to say that you may avoid $\phi$ ing even though ping would produce more of what's good, and even more bizarre to say, in the same circumstances, that you ought not $\phi$. This fact is usually taken to imply that the burden of proof lies with the non-consequentialist: she must identify some extremely compelling reason why you may or must avoid promoting more instances of goodness (Scheffler 1982; Foot 1985; Sturgeon 2010). And this is a burden many think the non-consequentialist can't possibly meet.

The property of being good for people, however, doesn't seem to have the same force. ${ }^{21}$ Let's consider some familiar kinds of example. Suppose that you're on a boat with four others who are dying of starvation. Only by sacrificing your own life (perhaps as food for them) will they survive. Someone might say that it would be better for those on the boat, for the group of boaters, if you sacrificed yourself. As we noted earlier, there are many philosophers who would, understandably, deny this-why is it better for the group given that you're a member of the group and

\footnotetext{
${ }^{20}$ A classic source for this view is Taurek (1977). In stating it we've assumed, for simplicity, that W1 and $\mathrm{W} 2$ are populated by the same inhabitants.

21 Thomson doesn't discuss the property of being good for people in Normativity. However, her criticism of the view that one must promote 'happier worlds' can be adapted, which is roughly what we do here (2008, pp.61-67). .
} 
would lose out enormously? - but we're going to grant it. It's enough for our purposes to notice that there's no oddity in saying that you still don't have to do it. You could reasonably reply that you aren't required to make such a costly personal sacrifice for the sake of the group. Now suppose that the only way to save the starving four is for you to kill a sixth person. Again the group would be better off if you did this. But there's still no oddity in saying that you shouldn't do it: the group would be better off, but you shouldn't treat the sixth person so badly just for its sake. Now, we might enlarge the group under consideration to look at what is good not just for the boaters but for people generally. And the points just made would still apply: it is perfectly acceptable in many cases to say that while people on the whole would benefit from a certain action, one still may or must avoid doing it.

We've argued that unqualified goodness has no place in moral theory. Of course, more specific ways of being good (for example, being good for people) might still have an important theoretical role to play, just not the simple and direct role that the sophisticated consequentialist envisages. What role do these more specific ways of being good play? We can't say here, but Thomson (2008, Chap. 12) offers a number of important proposals. Our aim was to contribute to an earlier stage of the dialectic. To quickly summarize, we presented an argument that isn't susceptible to the common objections targeting G\&T. If sound, the argument illustrates how one might responsibly draw substantive conclusions from observations about natural language. In particular, it shows that natural language considerations undermine standard consequentialism. Furthermore, we drew attention to a series of considerations that expand the threat beyond standard consequentialism. Along the way we acknowledged a couple of open questions. First, what do apparently predicative uses of 'good' really mean? Second, what role should more specific ways of being good play in moral theory? We hope to answer these questions in future work. For now we would just like to observe that G\&T seem to have been right all along: it seems that once you grant their observations about language you are compelled to accept their astonishing conclusion.

Acknowledgments We're fortunate to have many supportive friends, colleagues, and teachers. This project was much improved by their questions and comments. We would like to thank Dominic Baily, David Barnett, James Bondarchuk, Ross Cameron, Fabrizio Cariani, Jennifer Carr, Rebecca Chan, Daniel Elstein, Ephraim Glick, Aidan Gray, Sam Fleischacker, Chris Heathwood, Ulrike Heuer, Dave Hilbert, Paul Hovda, Kathrin Koslicki, Tony Laden, Heather Logue, Connie Meinwald, Bernhard Nickel, Graham Oddie, Ben Rohrs, Noël Saenz, Paolo Santorio, Sally Sedgwick, and Robbie Williams. One person deserves special recognition. We were first introduced to the question, is anything just plain good, in the Fall of 2005 at MIT, when Judith Jarvis Thomson taught a graduate seminar about normativity. Our thoughts have been heavily influenced by her work. We're extremely grateful to have had her as a teacher, and for her written comments on an earlier draft of this paper (though all remaining mistakes are our own). Finally, one author wishes to acknowledge the College of Liberal Arts \& Sciences at UIC, which supported the final stages of this project by means of an LAS Award for Faculty Research in the Humanities.

\section{References}

Arneson, R. (2010). Good period. Analysis, 70, 731-744.

Broad, C. D. (1930). Five types of ethical theory. London: Routledge.

Brown, C. (2011). Consequentialize This. Ethics, 121, 749-771. 
Devitt, M. (1980). "Ostrich nominalism" or "mirage realism”? Pacific Philosophical Quarterly, 61, 433-439.

Dewey, J., \& Tufts, J. H. (1908). Ethics. New York: Henry Holt.

Foot, P. (1985). Utilitarianism and the virtues. Mind, 94, 196-209.

Frankena, W. K. (1963). Ethics. Englewood Cliffs: Prentice-Hall.

Geach, P. (1956). Good and evil. Analysis, 17, 33-42.

Hinzen, W. (2006). Mind Design and Minimal Syntax. Oxford: Oxford University Press.

Kagan, S. (1998). Normative ethics. Boulder: Westview Press.

Kamm, F. (1992). Non-consequentialism, the Person as an End-in-Itself, and the Significance of Status. Philosophy \& Public Affairs, 21(4), 354-389.

Kennedy, C. (2007). Vagueness and grammar: The semantics of relative and absolute gradable adjectives. Linguistics and Philosophy, 30, 1-45.

Kennedy, C. (2012). Adjectives. In G. Russell, \& D. G. Fara, (Eds.), Routledge Companion to Philosophy of Language. New York: Routledge.

Korsgaard, C. (1983). Two Distinctions in Goodness. Philosophical Review, 92, 169-195.

Kraut, R. (2011). Against absolute goodness. Oxford: Oxford University Press.

Kripke, S. (1980). Naming and necessity. Cambridge: Harvard University Press.

Langton, R. (2007). Objective and Unconditioned Value. Philosophical Review, 116, 157-185.

Lewis, D. 1980. Mad pain and Martian pain. Readings in the Philosophy of Psychology 1, $216-222$. Reprinted in David Lewis, Philosophical Papers I, pp. 122-129. Page reference to this volume.

Moore, G. E. (1903). Principia ethica. Cambridge: Cambridge University Press.

Nunberg, G. (1978). The Pragmatics of Reference. Bloomington: Indiana University Linguistics Club. Parfit, D. (2011). On what matters (Vol. 1). Oxford: Oxford University Press.

Pidgen, C. (1990). Geach on "good". Philosophical Quarterly, 40, 129-154.

Quine, W. V. (1948). On what there is. The Review of Metaphysics, 2, 21-38.

Rawls, J. (1971). A theory of justice. Cambridge: Harvard University Press.

Rosen, G. (2012). Review of Judith Jarvis Thomson's normativity. Journal of Philosophy, 109(11), 676-681.

Ross, W. D. (1930). The right and the good. Oxford: Oxford University Press.

Schapiro, T. (2001). Three conceptions of action in moral theory. Nô̂s, 35(1), 93-117.

Scheffler, S. (1982). The rejection of consequentialism. Oxford: Clarendon Press.

Scheffler, S. (Ed.). (1988). Consequentialism and Its critics. Oxford: Oxford University Press.

Smart, J. J. C. 1973. An outline of a system of utilitarian ethics. In Utilitarianism: For \& against. Cambridge: Cambridge University Press.

Smith, M. (2010). On normativity. Analysis, 70, 715-731.

Sturgeon, N. (2010). Normativity. Analysis, 70, 744-753.

Taurek, J. (1977). Should the numbers count? Philosophy \& Public Affairs, 6, 293-316.

Temkin, L. (2012). Rethinking the good. Oxford: Oxford University Press.

Thomson, J. J. (1997). The right and the good. Journal of Philosophy, 94, 273-298.

Thomson, J. J. (2008). Normativity. Chicago: Open Court.

von Wright, G. H. (1963). The varieties of goodness. London: Routledge \& Kegan Paul.

Willenken, T. (2012). Deontic cycling and the structure of commonsense morality. Ethics, 122, 545-561.

Ziff, P. (1960). Semantic analysis. Ithaca: Cornell University Press. 